Open Access

\title{
Prevalence of human parvovirus B19 in Chinese plasma pools for manufacturing plasma derivatives
}

Junting Jia' ${ }^{1}$, Yuyuan Ma ${ }^{1 *}$, Xiong Zhao ${ }^{1}$, Yi Guo ${ }^{1,2}$, Chaoji Huangfu' ${ }^{1}$, Chi Fang ${ }^{1}$, Rui Fan ${ }^{1}$, Maomin Lv' Huiqiong Yin ${ }^{1}$ and Jingang Zhang ${ }^{1 *}$

\begin{abstract}
Background: Human parvovirus B19 (B19V) is a frequent contaminant of blood and plasma-derived medicinal products. To ensure the quality and safety of plasma-derived products, European regulations, Plasma Protein Therapeutics Association (PPTA) standard and FDA guidelines require testing of manufacturing plasma for parvovirus B19 DNA to limit the load of this virus. In China, however, there have been no related documentation and technical guiding principles for monitoring B19V, moreover, an adequate level of information on the prevalence of B19V in Chinese plasma donations is not available.

Findings: By using an in-house quantitative polymerase chain reaction ( $q P C R$ ) assay adapted for all three genotypes of B19V, 235 source plasma pools from three regional different Chinese manufacturers of blood products were screened and quantified. Results showed that $71.91 \%$ (169/235) of plasma pools were contaminated by B19V, with the concentrations of $5.18 \times 10^{2}-1.05 \times 10^{9} \mathrm{IU} / \mathrm{mL}$. Approximately $31.95 \%$ of the DNA-positive plasma pools were only moderately contaminated $\left(<10^{4} \mathrm{IU} / \mathrm{mL}\right)$, while $68.05 \%$ contained $>10^{4} \mathrm{IU} / \mathrm{mL}$.

Conclusions: The high level of B19V in plasma pools could present a great risk in plasma derivatives. Therefore, the implementation of B19V NAT (Nucleic Acid Testing) assays capable of detecting all B19V genotypes and discard donations with high titer B19V DNA for Chinese blood products manufacturers seems to be necessary.
\end{abstract}

Keywords: Human parvovirus B19, Quantitative PCR (qPCR), Source plasma pools

\section{Findings}

Human parvovirus B19 (B19V), a widespread human pathogen that be associated with a broad range of clinical manifestations, including erythema infectiosum (also called fifth disease), arthritis, transient aplastic crisis (TAC), chronic anemia, hydrops fetalis, and fetal death, can be transmitted via the administration of contaminated blood and plasma-derived products [1-5].

Due to the difficulty in removing and inactivating $\mathrm{B} 19 \mathrm{~V}$, the most effective measure for mitigating the risk of B19V transmission through plasma derivatives should be limiting the virus load in the manufacturing plasma pools. Since the early 21 st century, U.S. Food and Drug

\footnotetext{
* Correspondence: mayuyuan07@hotmail.com; zhangjg@nic.bmi.ac.cn 'Laboratory for Viral Safety of National Centre of Biomedical Analysis, Beijing Institute of Transfusion Medicine, No. 27 Taiping road, Haidian District, Beijing 100850, China

Full list of author information is available at the end of the article
}

Administration (FDA), European Pharmacopoeia (Ph. Eur.) and the Plasma Protein Therapeutics Association (PPTA) have developed a list of standards, proposing a limit of $10^{4} \mathrm{IU} / \mathrm{ml}$ for levels of B19V DNA in source plasma pools destined for manufacturing some or all kinds of plasma-derived products [6-10]. After the introduction of NAT (nucleic acid testing), both the prevalence and level of B19V DNA within plasma pools and their resulting products were significantly lowered [11]. B19V is now formally subdivided into three distinct genotypes $(1,2,3)$, which were defined as having approximately $10 \%$ divergence in overall DNA sequence [12]. Since all genotype variants can be contaminants of blood and blood-derived products, so the NAT assay as an in-process test used in the manufacturing of plasma-derived products must be able to detect all genotype variants $[13,14]$. 


\begin{tabular}{|c|c|c|c|c|c|c|c|c|c|c|c|}
\hline \multirow[t]{2}{*}{ Majority } & \multicolumn{11}{|c|}{ TGAAAGCAGCTTTTTCAACCTCATCACTCCAGGCGCCTGGAACAGTGAAACCCCGCGCTCTAGTACGCCCGTCCCCGGGACCAGTTCAGGAGAATCATTT } \\
\hline & 2000 & 2010 & 2020 & 2030 & 2040 & 2050 & 2060 & 2070 & 2080 & $2090=$ & \\
\hline $\begin{array}{l}\text { genotype1.seq } \\
\text { genotype2.seq } \\
\text { genotype3.seq }\end{array}$ & $\begin{array}{l}\ldots \\
\cdots \cdots \\
\cdots \cdots\end{array}$ & .... & & & & & & A..... & & & $\begin{array}{l}2097 \\
2069 \\
1989\end{array}$ \\
\hline Majority & GICGG & & CGAAG] & AGCCGCS & IGGGAG & CCITIT & $\mathrm{XCCXCT}$ & GACCAG & GTGAAC & AGITGGGGIIG & \\
\hline & 2100 & 2110 & 2120 & 2130 & 2140 & 2150 & 2160 & 2170 & 2180 & 2190 & \\
\hline
\end{tabular}

Fig. 1 Primers and probe-binding sequence of the in-house B19 DNA assays. The reference sequences of three B19 virus genotypes are aligned. Primers sequences were underlined with solid lines, and probe sequence was underlined with dashed line. B19 Genotype 1 sequence M13178 is used as reference sequence. For B19 Genotype 2 and 3, the Lali strain [GenBank: AY044266] and V9 strain [GenBank: NC-004295] are included in this alignment

In China, there have been no specific documentation and technical guidelines for monitoring B19V. There are about 33 manufacturers for blood products in China, however, B19V NAT screening of plasma has never been implemented in the manufacturing of plasma-derived products. Published data on the prevalence of B19V DNA in plasma pools are limited to the study by Zhang et al., whose investigation was restricted to 142 plasma pools from two of these manufacturers (one was located in the south of China, whereas the other's location was not mentioned), indicating that the positive rates of B19V DNA in plasma pools were relatively high (54.23\%) [15].

In this study, we aimed to test a total of 235 source plasma pools, collected between 2008 and 2013, from other three Chinese blood products manufacturers (Manufacturer A, B and C, respectively located in central, northern and south-western China). The collections of plasma samples were approved by the National Health and Family Planning Commission of the People's Republic of China, and all of the donators provided informed consent. Each batch of the plasma pools consisted of 2000 to over 8300 donations. Each donation mixed in the plasma pools was tested for aminotransferase (ALT), anti-syphilis, anti-HIV 1/2, HBsAg and anti-HCV before pooling. All the donations were confirmed to be qualified according to the requirements of Pharmacopeia of the People's Republic of China [16]. Viral DNA was extracted from a volume of $200 \mu \mathrm{L}$ pooled source plasma by using the High Pure Viral Nucleic Acid Kit (Roche Diagnostics, Mannheim, Germany) according to manufacturer's instructions. Nucleic acids were eluted from the filter column with $50 \mu \mathrm{L}$ of nuclease-free double-distilled water and were stored at $-20^{\circ} \mathrm{C}$ until further use.

Quantification of B19 DNA was performed by using an in-house developed qPCR assay adapted for all three genotypes of B19V. Primers B19F (5'-CGGGACCA GTTCAGGAGAAT-3), B19R (5'-CCCAACTAACAG TTCACGAAACT-3') and probe B19P (5'-AATCATTT GTCGGAAGCCCAGTTTCC-3') were designed to specifically amplify a 121-bp fragment derived from the NS1 gene of B19V (nucleotides 2073-2193, GenBank accession no.
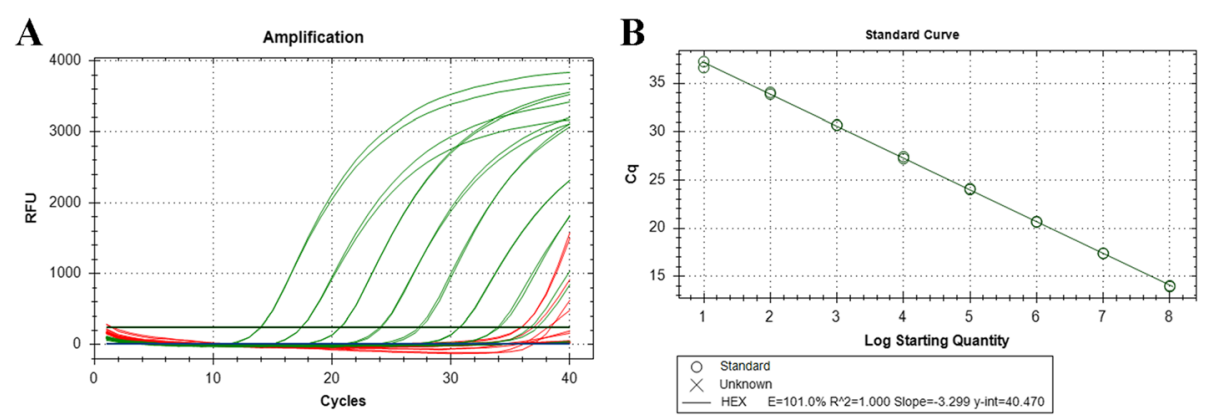

Fig. 2 Standard curve of the real-time qPCR assay for B19V DNA. a Amplification plots showing the testing in duplicate of a 10-fold dilution series containing standard plasmid of B19V from $1 \times 10^{8}$ to $1 \times 10^{1}$ template copies per $\mu \mathrm{L}$, and the IC plasmid at 120 copies per reaction. $\mathbf{b}$ Real-time PCR standard curve generated from plasmid DNA amplification plots(a). The $x$-axis represents B19V standard plasmid in 10-fold dilutions and the $y$-axis represents the fluorescence data used for Cq determinations. The assay was linear in the range of $1 \times 10^{8}$ to $1 \times 10^{1}$ template copies per $\mu$ l, with an $R^{2}$ of 1.000 , the slope value of -3.299 and reaction efficiencies of $101.0 \%$ 
Table 1 Distribution of the B19V DNA load in source plasma pools

\begin{tabular}{|c|c|c|c|c|}
\hline \multirow[t]{2}{*}{ B19V DNA load (IU/mL) } & \multicolumn{4}{|c|}{ Number of lots (\%) } \\
\hline & Manufacturer A & Manufacturer B & Manufacturer C & Total \\
\hline $10^{9} \sim 10^{10}$ & $1(0.71)$ & 0 & $1(1.35)$ & $2(0.85)$ \\
\hline $10^{8} \sim 10^{9}$ & $7(4.96)$ & $2(10.00)$ & $1(1.35)$ & $10(4.26)$ \\
\hline $10^{7} \sim 10^{8}$ & $4(2.84)$ & $4(20.00)$ & $2(2.70)$ & $10(4.26)$ \\
\hline $10^{6} \sim 10^{7}$ & $5(3.55)$ & $2(10.00)$ & $9(12.16)$ & $16(6.81)$ \\
\hline $10^{5} \sim 10^{6}$ & 19 (13.48) & $4(20.00)$ & $8(10.81)$ & $31(13.19)$ \\
\hline $10^{4} \sim 10^{5}$ & $36(25.53)$ & $5(25.00)$ & $5(6.76)$ & $46(19.57)$ \\
\hline Positive $\sim 10^{4}$ & $32(22.70)$ & $3(15.00)$ & 19 (25.68) & $54(22.98)$ \\
\hline Number of positive lots & $104(73.76)$ & $20(100.00)$ & $45(60.81)$ & $169(71.91)$ \\
\hline Number of negative lots & $37(26.24)$ & 0 & $29(39.19)$ & $66(28.09)$ \\
\hline Number of lots tested & 141 & 20 & 74 & 235 \\
\hline
\end{tabular}

M13178.1) (Fig. 1). An exogenous competitive IC (internal control) contained the identical sequence of the B19 target sequence but with an altered probe hybridization site (ICP: 5' -AATTCGATCTTGGACCAGCAGTTCTC-3'), was included in each sample to prevent false negative results. This allows co-amplification of B19V and IC and co-detection of HEX (5-Hexachlorofluorescein) or FAM (6-carboxyfluorescein) labeled probes respectively. Three microliters of DNA was added to a reaction mixture (in a final volume of $20 \mu \mathrm{L}$ ) containing $10 \mu \mathrm{L}$ of Platinum Quantitative PCR SuperMix-UDG (Invitrogen Life Technologies, Paisley, United Kingdom), 500nM of each primer, and 250nM of each probe for amplification of DNA from the B19V and IC. Amplification and detection were carried out on the Bio-Rad MiniOpticon Real-Time PCR System (BioRad Laboratories, Hercules, USA) with the following thermal cycle conditions: $2 \mathrm{~min}$ of incubation at $50{ }^{\circ} \mathrm{C}$, 2 min of pre-denaturation at $95^{\circ} \mathrm{C}, 40$ cycles in two steps each $\left(95{ }^{\circ} \mathrm{C}\right.$ for $9 \mathrm{~s}, 60{ }^{\circ} \mathrm{C}$ for $30 \mathrm{~s}$ ). Standard curves were generated with serial log 10 dilutions ranging from $10^{8}$ to $10^{1}$ copies per $\mu \mathrm{L}$ of the B19V standard plasmid containing the 121-bp PCR product. One hundred and twenty copies of the IC plasmid were included in each well and all samples were analyzed in duplicate. The assay was shown to be linear over this eight orders of magnitude. The IC DNA could be detected when B19V plasmid lower than $10^{3}$ copies per $\mu \mathrm{L}$ and in the no template control (NTC) well (Fig. 2). The performance of this NAT assay was evaluated with the 1st WHO International Reference Panel for Parvovirus B19 Genotypes for NAT based assays (NIBSC code: 09/110). This assay was able to detect all three B19 virus genotypes with the sensitivity of 5 copies per reaction, and the conversion ratio from copies to IU is 5.08:1, indicating that $5.08 \mathrm{~B} 19 \mathrm{~V}$ copies $/ \mathrm{mL}$ measured by our real-time qPCR assay was equivalent to $1 \mathrm{IU} / \mathrm{mL}$.

As indicated in Table 1, $72 \%(169 / 235)$ of the samples contained detectable levels of $\mathrm{B} 19 \mathrm{~V}$ and the amount of DNA ranged from $5.18 \times 10^{2}$ to $1.05 \times$ $10^{9} \mathrm{IU} / \mathrm{mL}$ plasma. Forty-nine percent $(115 / 235)$ of plasma pools contained B19V DNA at concentrations exceeding $10^{4} \mathrm{IU} / \mathrm{mL}$. In the case of manufacturer $\mathrm{B}$, the positive rate of $\mathrm{B} 19 \mathrm{~V}$ DNA in plasma pools was $100 \%$, higher than that from manufacturer $\mathrm{A}$ (73.76\%) and manufacturer C (60.81\%). Positive rates of B19V DNA in plasma pools from three manufacturers were

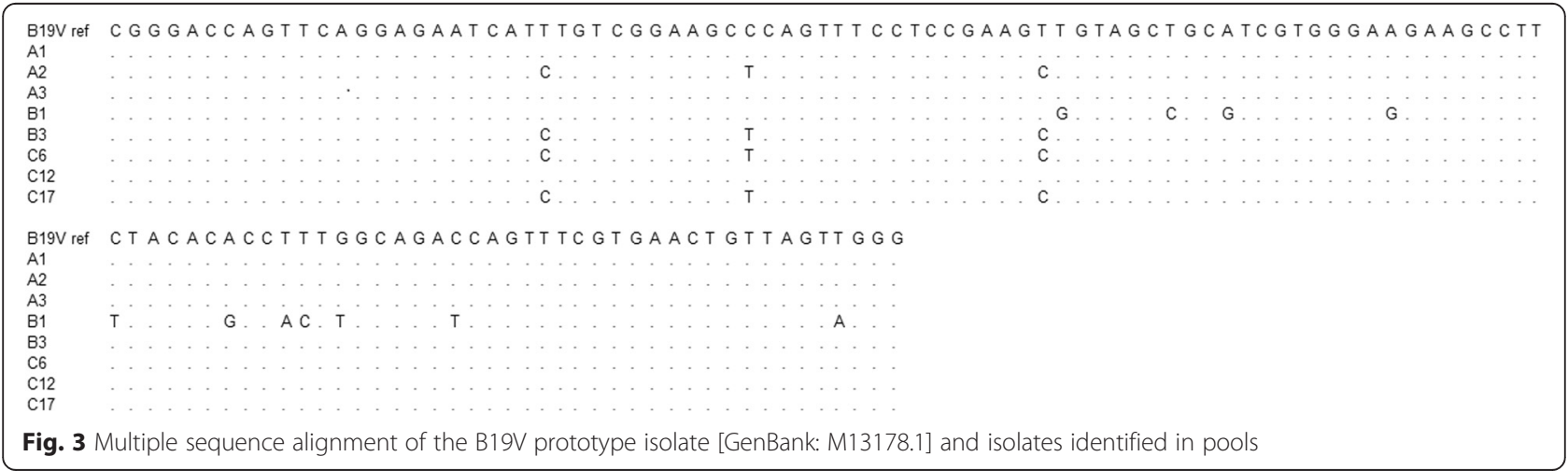


significantly different $\left(\chi^{2}=12.566, \quad P=0.002<0.05\right.$, chi-square test). Above results showed that both of the prevalence and levels of B19V DNA in plasma pools tested in our study were higher than that of previous reports in China $(54.20 \%$ ) and investigations in other countries before NAT was introduced $(56.10 \%$ $59.68 \%)$ $[15,17,18]$. Besides, there were large differences among the positive rates of industrial plasma pools of five manufactures (three in our study and the other two in previous report) in China, ranging from 30 to $100 \%$. These diversities may reflect geographic differences in the spread of the virus in diverse parts of the world, methodological differences in diagnostic procedures, differences in sample size, or differences in number of plasma units within each pool sample.

To confirm the accuracy of the NAT procedure, PCR products of the positive samples were cloned into pMD18-T vector (Takara Bio, Dalian, China) and sequenced using ABI 3730 and accessories. Then the sequences were aligned with the sequence of B19V prototype isolate (GenBank accession no. M13178.1) using DNAStar software package. Sequencing and alignment of amplification products of the positive samples revealed that they exhibited $90.24 \% \sim 100 \%$ identity with the prototype (Fig. 3).

In conclusion, the data present demonstrates a relatively high prevalence of $\mathrm{B} 19 \mathrm{~V}$ in Chinese plasma pools. Therefore, to reduce the risk of B19V transmission, the implementation of B19V NAT assays capable of detecting all $\mathrm{B} 19 \mathrm{~V}$ genotypes and discard donations with high titer B19V DNA for Chinese blood products manufacturers seems to be necessary.

\section{Abbreviations \\ B19V: Human parvovirus B19; qPCR: Quantitative polymerase chain reaction: NAT: Nucleic acid testing; PPTA: Plasma Protein Therapeutics Association; WHO: World Health Organization; FDA: Food and Drug Administration; Ph. Eur.: European Pharmacopoeia; NIBSC: National Institute for Biological Standards and Control; IC: Internal control.}

\section{Competing interests}

The authors declare that they have no competing interests.

\section{Authors' contributions}

JJ searched data, performed the experiments, collected and analyzed the data, and wrote the manuscript; YM and JZ designed the study and gave a critical view of manuscript writing; and $X Z, Y G, C H, C F, R F, M L$, and $H Y$ provided help to JJ during the process of experiments. All the authors read and approved the final manuscript.

\section{Acknowledgments}

This study was supported by Natural Science Foundation of Beijing (Grant no. 7132144) and National High-tech R\&D Program of China (863 Program) (Grant no. 2012AA021902).

\section{Author details}

'Laboratory for Viral Safety of National Centre of Biomedical Analysis, Beijing Institute of Transfusion Medicine, No. 27 Taiping road, Haidian District, Beijing 100850, China. ${ }^{2}$ Shaanxi Blood Center, Xi'an, China.
Received: 7 July 2015 Accepted: 30 September 2015

Published online: 06 October 2015

\section{References}

1. Anderson MJ, Jones SE, Fisher-Hoch SP, Lewis E, Hall SM, Bartlett $\mathrm{CL}$, et al. Human parvovirus, the cause of erythema infectiosum (fifth disease)? Lancet. 1983;1(8338):1378.

2. Brown KE. The expanding range of parvoviruses which infect humans. Rev Med Virol. 2010;20(4):231-44.

3. Young NS, Brown KE. Parvovirus B19. N Engl J Med. 2004;350(6):586-97.

4. Koenigbauer UF, Eastlund T, Day JW. Clinical illness due to parvovirus B19 infection after infusion of solvent/detergent-treated pooled plasma. Transfusion. 2000;40(10):1203-6.

5. Soucie JM, Monahan PE, Kulkarni R, De Staercke C, Recht M, Chitlur MB, et al. Evidence for the continued transmission of parvovirus B19 in patients with bleeding disorders treated with plasma-derived factor concentrates. Transfusion. 2013;53(5):1143-4.

6. Guidance for industry: nucleic acid testing (NAT) to reduce the possible risk of parvovirus B19 transmission by plasma-derived products. U.S. Department of Health and Human Services, Food and Drug Administration, Center for Biologics Evaluation and Research. July 2009. http://www.fda.gov/ BiologicsBloodVaccines/GuidanceComplianceRegulatoryInformation/ Guidances/Blood/ucm071592.htm. Accessed 10 May 2015.

7. Human anti-D immunoglobulin. European Pharmacopoeia (version 5.0). France; 2005. p. 1732-33.

8. Human plasma (pooled and treated for virus inactivation). European Pharmacopoeia (version 5.0). France; 2005. p. 1747-48.

9. PPTA voluntary standard parvovirus B19. Plasma Protein Therapeutics Association. August 2003.http://www.pptaglobal.org/component/search/ ? searchword=B19\&searchphrase=all\&ltemid=101. Accessed 10 May 2015

10. QSEAL NAT testing standard (Version 2.0). the PPTA QSEAL Standards Committee. June 2013. http://www.pptaglobal.org/images/qseal/ NATTestingV2.pdf. Accessed 10 May 2015.

11. Geng Y, Wu CG, Bhattacharyya SP, Tan D, Guo ZP, Yu MY. Parvovirus B19 DNA in Factor VIII concentrates: effects of manufacturing procedures and B19 screening by nucleic acid testing. Transfusion. 2007;47(5):883-9.

12. Servant A, Laperche S, Lallemand F, Marinho V, De Saint Maur G, Meritet JF, et al. Genetic diversity within human erythroviruses: identification of three genotypes. J Virol. 2002;76(18):9124-34.

13. Baylis SA. Standardization of nucleic acid amplification technique (NAT)based assays for different genotypes of parvovirusB19: a meeting summary. Vox Sang. 2008;94(1):74-80.

14. Modrow S, Wenzel JJ, Schimanski S, Schwarzbeck J, Rothe U, Oldenburg J, et al. Prevalence of nucleic acid sequences specific for human parvoviruses, HAV and HEV in coagulation factor concentrates. Vox Sang. 2011;100(4):351-8.

15. Zhang W, Ke L, Changqing L, Zhang Y, Li W. Parvovirus B19V DNA contamination in Chinese plasma and plasma derivatives. J Transl Med. 2012;10:194

16. Chinese Pharmacopoeia Commission. Human plasma for manufacturing plasma derivatives. In: The Pharmacopoeia of the People's Republic of China (2010 Chinese edition, volume 3). China. 2010. p. 12-4.

17. Schmidt I, Blümel J, Seitz H, Willkommen H, Löwer J. Parvovirus B19 DNA in plasma pools and plasma derivatives. Vox Sang. 2001;81(4):228-35.

18. Koppelman MH, Cuypers HT, Emrich T, Zaaijer HL. Quantitative real-time detection of parvovirus B19 DNA in plasma. Transfusion. 2004;44(1):97-103. 